\title{
INFECÇõES BACTERIANAS TRATADAS COM Ro 6-2580*
}

\author{
Paulo F. A. Lopes ** Walber Vieira *** J. Rodrigues Coura **** \\ Ronald S. Gruenbaum ***** e Maria José Conceição*****
}

\begin{abstract}
Nova combinação medicamentosa composta de sulfametoxazol e trimetoprim ("Bactrim"), com efeito bactericida sôbre germes Gram negativos e Gram positivos, foi ensaiada no tratamento de 15 casos de salmonelose e 9 casos de infecções bacterianas. Os resultados foram favoráveis, tanto nas salmoneloses, como em infecçóes por estafilococos, shigelas, pneumococos e coliformes. A remissão do estado tóxico nos casos de febre tifóide foi observada dentro de 48 horas, e o tempo médio para desaparecimento da febre e demais sintomas, nessa infecção, foi de 3 dias. Foram constatados efeitos secundários em alguns pacientes, tais como hipertermia medicamentosa, farmacodermia, vômitos, linfomonocitose e eosinofilia, possivelmente relacionados a posologia excessiva, $e$ todos remissiveis. Os autores concluem pela utilidade do novo medicamento na terapêutica de salmoneloses, estafilococcias e outras infecções.
\end{abstract}

\section{INTRODUÇÃO}

O Ro 6-2580 ("Bactrim" Roche) é uma associação de sulfametoxazol e trimetoprim, dois compostos bacteriostáticos que interferem na sintese do ácido fólico, em diversos tipos de microrganismos. Há indicaçōes, na literatura, de que essa combinação medicamentosa resulta em efeito potencializado (2) e é dotada de ação bactericida contra as principais espécies bacterianas, Gram positivas e Gram negativas, mais freqüentes em patologia humana $(3,6)$.
O Ro 6-2580 foi ensaiado por diversos autores no tratamento de salmoneloses, após a verificação pioneira de Sueri e cols. (8); são particularmente interessantes as observaçōes de Semprevivo e cols. (7), mostrando resultados superiores aos obtidos com o cloranfenicol, no tratamento de 100 crianças com febre tifóide e paratifóide, assim como o trabalho de Galvão e Ulmacher (5), que descrevem um caso complicado de tifóide, tratado sucessivamente com várias séries de cloranfenicol, estreptomicina e ampicilina, desenvolvendo perfuraçōes intestinais com quadro de abdomen agudo.

* Trabalho da Disciplina de Doenças Infecciosas e Parasitárias da F.M.U.F.R.J. (Prof. J. Rodrigues Coura). Apresentado ao VI Congresso da Socledade Erasileira de Medicina Tropical, Pôrto Alegre, 22 a 25 de fevereiro de 1970.

* * Prof assistente.

*** Auxiliar de ensino.

$* * * *$ Prof. regente.

***** Internos.

Fiecebido para publicacão em 5_5-70. 
Também em outras infeccōes, particularmente dos apareinos respiratório $\mathrm{e}$ urinário, os resultados obtidos com o Ro 6-2580 parecem bastante favoráveis (1, 4, 9 ), salientando-se as infeccoos por $H$. influenzae e as estafilococoias resistentes à penicilina

Nosso estudo com o novo antibacteriano foi iniciado já há algum tempo, ainda na fase experimental do medicamento, e abrange o tratamento de infecçoes bacterianas diversas, sobretudo salmoneloses.

\section{MATERIAL E METODOS}

O Ro 6-2580 foi administrado por via oral, sob a forma de comprimidos contendo $400 \mathrm{mg}$ de sulfametoxazol e $80 \mathrm{mg}$ de trimetoprim. Os pacientes se achavam internados em nosso serviço, e distribuidos nas seguintes categorias diagnósticas (Quadro I)

\section{QUADRO I}

\section{INFECCÕES BACTERIANAS TRATADAS COM RO 6-2530. CASUISTICA}

Categcria diagnóstica

salmoneloses

estafilococcias

shigelose

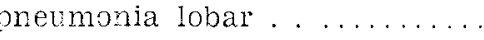

infenção ürinária . . .........

N.o de

casos

Observaçōes

15

6

1

1

1
6 s. typhi, 9 \&. sp.

2 furunculoses, 4 uretrites

Shigella sp.

diploccco Gram positivo

Escherichia coli
O diagnóstico foi sempre comprovado por cxames de laboratorio, procedendo-se a h mo e ccoronnitura e reacão de Nidal ros casos de salmone'ose.

A idade dos pacientes variou de 19 a 44 anos; 17 eran do sexo masculino, e 7 do feminino.

A posologia administrada inicialmente seguiu as recomendações gerais forneridas pelos fabricantes na faso de ensaios clínicos; nos casos de salmonelose, 6 comprimidos disrios durante 5 dias seguindo-se 3 crmprimidos ao dia durante 10 a 14 dias, para odultos; posteriomente, a dose foi adaptada ao péso de cada paciente, administrando-se 40 a $50 \mathrm{mg} / \mathrm{Kg}$ dia, durante 4 a 6 dias, c redur indo-se para 20 a 20 mo $\mathrm{Kg}$ dia ros 5 a 10 dias seguintes.

A duracão do tratamento esteve na dependêncla do tipo e da gravidade do process infeccioso: cs primeiros 6 casos de salmoncloze, como ficou dito acima, iniciaram o tratamento com 6 comprimidos dínos, mas a coorência de efeitcs sesundários obrigcu a variaçés na duraçáo do tratamento, desde 3 dias até 14 dias. Já os nove casos seguintes receberam close pa- dronizada segundio o fêso corporal, e o tratamerto loi mantido por tempo constante. os portadores de infeccōes estafilocócicas foram tratados por 10 dias, assim como o coso do infescāo urinária. O pasiente com shigelose teve seu tratamento feito em 6 dias, e o caso de pneumonia lobar, em 7 dias.

C contrôle de todos os parientes foi basoado na cvolução clinica e em comprovacés laboratoriais, cuando necessário. Nos pazientes com salmoneloses, o período de ojecrvação prs-tratamento estendeu-se de 6 a 12 meses, com coproculturas freqüentes e verificaça da queda de títulos na rro-aglutinação de Widal.

\section{RESULTADOS}

Im vista de sua particular importância, os resultados obtidos no tratamento de salmoneloses são considerados separadamente (Quadro II)

O resultado terapético nas outras categorias nosológicas mostrou-se também raveravel. Entre os 9 casos tratados (shigelose, furunculose, uretrite, pneumonia 
lobar, infecção urinária) houve residiva em apenas 1 paciente com furunculose por estafilococos, tendo os demais apresentado desaparecimento do quadro infeccioso permanecendo posteriormente assintomático.

Quanto aos efeitos secundários, observou-se hipertermia medicamentosa no paciente n. ${ }^{\circ}$, no nono dia de tratamento após 4 dias de apirexia; essa reação desapareceu com a redução da dose de 2880 $\mathrm{mg}$ diários para $1440 \mathrm{mg}$ ao dia. O caso n. ${ }^{\circ} 3$ apresentou também reação hipertérmica durante os 6 dias de tratamento: a suspensão da terapêutisa fêz desaparecer a febre, assim como os demais sintomas da infecção. Contrôles repetidos por período superior a 6 meses não revelaram recaída clínica cu laboratorial nêsses dois pacientes. O caso n. ${ }^{\circ} 4$ apresentou farmacoder- mia no terceiro dia de tratamento; interrompida a medicação recuperou-se em uma semana, mas não voltou para contrôles posteriores. O paciente n. ${ }^{\circ} 5$ teve nauseas e vômitos no terceiro dia de tratamento; com a correção da posologia, o efeito colateral desapareceu, e a medicação foi mantida por mais 10 dias. o caso n. ${ }^{\circ} 6$ revelou linfomonocitose, que se normalizou após a suspensão da terapêutica, no nono dia (Quadro II). Nos pacientes de ns. 7 a 15, já tratados com posologia proporcional ao pêso, observou-se apenas ocorrência passageira de linfomonocitose e eosinofilia, em 6 casos.

\section{DISCUSSÃO E CONCLUSÕES}

Os resultados verificados no presente ensaio confirmam a eficácia verificada por

\section{QUADRO II}

\section{SALMONELOSES TRATADAS COM R06 -2580. ESQUEMAS E RESULTADOS}

\section{saso n" Posclogia diária $e$ duração}

16 comp. $\times 14$ dias

$26 \mathrm{c} \times 9 \mathrm{~d} \cdot 3 \mathrm{c} \times 4 \mathrm{~d}$

$36 \mathrm{c} \times 6 \mathrm{~d}$

curado

$46 c \times 3 d$

trat. interrompido

5

$$
\begin{aligned}
& 6 . \times 3 d \div 25 \mathrm{mg} \mathrm{Kg} \mathrm{x} \\
& \times 10 \mathrm{~d}
\end{aligned}
$$

$64 \mathrm{c} \times 9 \mathrm{~d}$

curado

curado

curado

curado

\section{Evolucão clinica \\ Observações}

7 a 15 40-50 $\mathrm{mg} \mathrm{Kg} \times 4-60$

desapareeinento do es20-25 mg $\mathrm{Kg} \times 5-10 \mathrm{~d}$ tado tóxico, em 48 his.. e da febre e outios sintomas em 3 dies.
Contrōles pós-trat. negat. ( 6 a 12 meses).

hiperternia no 9." dia; contrôles pós-trat. negativos.

hipertermia durante trat.; contrôles pós-trat. negativos.

farmacodermia no $30^{\circ}$ dia; sem contrôle ulterior.

vômitos no $3 .^{\circ}$ dia; contrôles pós-trat. negativos.

linfomonocitose; contrôles pós-trat. neg.

controles pós-trat. neg.: posologia relacionada ao péso corporal. 
Semprevivo e cols. no tratamento da febre tifóide. Dos quinze casos de salmonelose que tivemos a oportunidade de observar, apenas um não foi controlado a longo prazo; foi o caso n. ${ }^{\circ} 4$, que apresentou farmacodermia e teve seu tratamento interrompido no terceiro dia, perdendo o contato com êste serviço ao fim da primeira semana. A rapider da regressão dos sintomas, com desaparecimento do estado tóxico característico da febre tifóide em 48 horas, assim como da febre em 3 dias em média, constitue forte argumento em favor da nova combinacão medicamentosa. E de particular interêsse o fato de que nenhum dos pacientes tratados voltou a eliminar salmonelas pelas fezes, após o tratamento; tivemos o cuidado de realizar contrôles freqüentes e repetidos, por período que variou de 6 a 12 meses. Êsse achado vem confirmar as constataçóes de Sueri e cols., que não encontraram portadores após tratamento com o Ro 6-2580. A posclogia merece especial cuidado, pois na nossa série de pacientes com salmonelose só observamos efeitos secundários de importância no grupo inicial de casos tratados, quando não tínhamos ainda estabeiecido um esquema adequado de dose por quilograma de pêso corporal.

Com referência aos outros processos infecciosos estudados nêste trabalho, confirmamos também a eficácia do Ro 6-2580; o medicamento mostrou-se ativo em estafilococcias e em dois casos de infecção por
Gram negativos. Evidentemente, não nos sentimos com liberdade para conclusões definitivas. em vista da casuística relativamente reduzida; mas pelo menos no que se refere à febre tifóide e outras salmoneloses, nossos resultados são inequívocos.

Resta comentar o problema referente aos efeitos secundários. Observamos, em dois pacientes com salmonelose, o aparecimento de reação hipertérmica que não parece ter sido ligada ao estado infeccioso, em vista da evolução geral do quadro. Outro paciente do mesmo grupo apresentou vômitos, no terceiro dia de tratamento, que desapareceram com a suspensão da droga. Um dos casos teve, também no terceiro dia, reação de hipersensibilidade que se traduziu por farmacodermia; foi o único caso não controlado a longo prazo e sôbre o qual não podemos ter certeza da cura da infecção, apesar da regressão da sintomatologia na semana em que permaneceu hospitalizado. Finalmente, observamos o aparecimento de linfomonocitose e eosinofilia, em alguns casos, sem ocorrência de comprometimento clínico.

Podemos concluir, com base no present3 ensaio, que o Ro 6-2580 é medicação promissora no tratamento da febre tifóide e de outras salmoneloses, assim como em infeccões por estafilococos. Parece induzir menos reações secundárias que outros antibacterianos, se fôr estabelecida posologia correta.

A new anti-infectious compound "Bactrim". sulfamethoxazole + trimethoprim), with bactericidal effect upon Gram positive and Gram negative bacteria, was assayed in the treatment of 15 cases of salmonelosis and 9 cases of varied bacterial infections. . Results were favourable both in salmonelosis and in infections produced by staphlococcus, shigela, pneumococcus and coliform bacilli. Remission of toxemia in typhoid fever ocurred within 48 hours, and fever and other symptcms disappeared before the third day of treatment. Side effects were observed in some patients, represented by hyperthermia, skin reaction, vomiting and lymphomonocylosis and eosinophilia, possibly dose-related and always disappearing with suspension of the treatmente or reduction of the posology. The authors are of the opinion that the new compound is a promissing therapy for typhoid fever and bacterial infections in a general way. 


\section{BIBLIOGRAFIA}

1. BLOEDNER, C. D.: - "Die Behandlung. akuter Schübe der chronisch rezidivierender Bronchitis mit Gantanol-Trimethoprim (Roche)'. Chemotherapy 14 (suppl.), 1969.

2. BïHNI, E. -. "The chemotherapeutic activity of combinations of trimethoprim and sulphamethoxazole in infections in mice". Symposium on the sinergy of trimethoprim and sulphonamides, Londres, 9 maio, 1969.

3. BUSHBY, S. R. M. e HITCHINGS, G. H.: - "Trimethoprim, a sulphonamide potentiator". Brit. J. Pharmacol. 33: 72-90, 1968 .

4. DREW, C. D. M., HUGHES, D. T. D., FOWLE, A. S. E. A CASSELL, M. A.: - "Effective tratment of chronic bromehitis with short term trimethoprim and sulphamethoxazole". V Congresso Internacional de Quimio. terapia, Viena, 1967.
5. GALVÃO, F. A. e ULMACHER, R, : — "Um caso de perfuração intestinal por febre tifóide tratado com o Ro 6-2580/11. "XXI Cong. Brasileiro de Gastrent.; Recife, Julho, 1969

6. GARROD, L. P. e WATERWORTH, P. M. . "The antibacterial action of trimethoprim". V Congresso Internacional de Quimioterapia, Viena, 1967.

7. SEMPREVIVO, L., GAMBOA, R., SILVA, M. e SAITUA, M. T. - "Treatmeni with Bactrim of typhoid and paraiyphoid fever in children". VI Congresso Internacional de Quimioterapia, 'óquio, 1969.

8. SUERI, L. A., CALONGHI, G. F. e IELASI, G.: - "Sperimentazione in vivo del Ro 6-2580 in soggetti con tossinfezione alimentare da Salamonelle 0 in portatori di Salmonelle. Nota preliminare". G. Mal. infectt. 9: 831833, 1968 .

9. "Trimethoprim in the urinary tract". Brit. med. J., I: 525-526, 1969. 
(Continuação da página 344)

Art. 6. ${ }^{\circ}$ - O parecer da Comissão Jul- gulamento serão resolvidos pelo Diretor gadora deverá ser emitido até o início do Congresso da Sociedade Brasileira de Medicina Tropical nos anos pares, quando o prêmio será solenemente entregue ao vencedor. A primeira entrega de prêmio será em 1970 .

do Instituto de Tropicologia Médica em conformidade com o Presidente da Sociedade Brasileira de Medicina Tropical e se fôr o caso com a Firma Patrocinadora e ao canđidato não caberá nenhum recurso ao parecer da Comissão Julgadora ou de Art. $7 .^{\circ}$ - Os casos omissos neste reseu Presidente. 